\title{
\begin{tabular}{llllllllllllllll}
$T$ & $U$ & $R$ & $K$ & $T$ & $A$ & $R$ & $I$ & $H$ & & $K$ & $U$ & $R$ & $U$ & $M$ & $U$ \\
\hline
\end{tabular} \\ BELLETEN
}

\section{DURMAZ KOLEKSIYONU'NDAKI BÜYÜK ISKENDER TETRADRAHMI DEFINESI}

\section{MELIH ARSLAN}

Bu define, Ankara Anadolu Medeniyetleri Müzesi koleksiyoneri, Sn. Mehmet Durmaz ${ }^{1}$ Koleksiyonu'ndadır. 11-42 envanter numaralarıyla kayıtlı bulunan definede, 32 adet gümüss tetradrahmi bulunmaktadır. Sikkelerin büyük çoğunluğunun doğu darphanelerinde, pek azının da batı darphanelerinde basılmıș olduğu tespit edilmiştir. Definede, Alexander III (Büyük İskender)'ün kendi döneminde bastırılmıș pek az örneğine karşın, definenin çoğunluğunu İskender'in hemen sonrasına ait posthumous (hatıra) İskender sikkeleri olușturmaktadır².

Define sikkelerinin ön yüzlerinde, aslan postu bir başlık giymiş genç Herakles başı ve arka yüzlerinde ise Zeus, tahtta sola oturuyor, sağ elinde kartal ve sol elinde asa tutmaktadır.

M.Ö. 336 yılında kral olan İskender, yeni gümüşs sikkeler basturmıştur. Bu gümüşs sikkelerdeki en önemli yenilik, bu sikkelerin yerel Makedonya ağırlık ölçüsüne göre değil, Attika ağırlık ölçüsünde basılmış olmasıdır. Bu şekilde İskender, kendi gümüş sikkelerini dönemin en yaygm ticari sikkeleri olan Atina 'baykuşlu' tetradrahmileriyle doğrudan değiştirilebilir hale getirmişti; yani İskender gümüş sikkeleri Atina gümüş tetradrahmileriyle aynı değerde

* Melih Arslan, Anadolu Medeniyetleri Müzesi, 06240 Hisar/Ankara; e-mail: arslanmelih06@ hotmail.com

${ }^{1}$ Bu değerli defineyi yayınlamama izin verdiği için, Sn. Mehmet Durmaz'a teşekkür ederim. Ayrıca bilgisayardaki metin düzenlemeleri ve haritaların çizimi için Sn. Oğuz Bostancı'ya şükranlarımı sunarım.

${ }^{2}$ Price (1991), sf. 85-502. 
kabul ediliyordu. İskender gümüș sikkesi tüm Akdeniz dünyasında geçerli bir para olmuștu. Birkaç on yıl içinde İskender'in ve ardıllarının (diadokhlar) tasarrufunda olan zengin metal kaynakları sayesinde bu gümüș para, Atina sikkelerini piyasadan sürdü ve İskender İmparatorluğu' nun en önemli ticari parası durumuna geldi; ünü imparatorluğun sınırlarınm ötesine taştu. Öyle ki, 5 yeni İskender Tetradrahmisinin değeri 1 altun statere eşit sayıldı. Bu da gösteriyor ki, bu yeni tip tetradrahmiler çok değerli bir para idi.

İskender para reformunun en ilginç özelliği, yeni tipler seçmiş olmasıydı. Makedonya krallarının mitolojik atası olan Herakles, Makedonya'da uzun zamandır bir sikke tipi olarak kullanllyordu. Tahtta oturan Zeus ise babası Philip II'nin tetradrahmilerinin ön yüzünde ayakta betimlenen Zeus'un bir versiyonuydu. Fakat Makedonya ile olan çağrıșımlar bir kenara, bu tiplerin herkesçe tanınmış olması ve çekicilikleri nedeniyle de seçildiklerine kuşku yoktur. Zeus ve Herakles'i her Helen tanıyor ve saygı gösteriyordu. Herakles, soygunculara ve barbarlara karşı dövüșerek cennete gitmeye hak kazanmıș bir kahramandı. Zeus ise Panhellen tanrıların en büyügü olup, tanrıların ve insanların babasıydı. Daha geç dönemlerde bu tipler, İskender' in doğu objelerine yönelmesine paralel olarak, doğu figürleriyle özdeșleștirilmeye başlandı. Herakles, Malkart ya da Gilgamıș'la özdeşleștirilirken, oturan Zeus da doğunun yerel tanrısı Baal ile benzeșiyordu³. Böylece ön yüzdeki genç Herakles portresi ile kendisini ve arka yüzdeki Zeus tipi ile de kendisinin tanrılar soyundan geldiğini ifade etmeye çalışmaktadır. Bu sikke tipi İskender ile bașlamıș, onu takip eden tüm krallar tarafından da kullanılmıștır. Bu para tipi Makedonya'dan Hindistan'a kadar olan coğrafi bölgede en revaçta para olarak 200 yll boyunca kullanılmış ve tedavülde kalabilmiștir. Bu tipi en son kullanan kral, Pontus Kralı Mithradates VI (M.Ö. 120-63) olmuştur. Görüldüğü üzere bu para tipi, klasik dönem baykuş tasvirli Athena tetradrahmilerinden sonra, tüm Helenistik dönem içinde değerinden bir şey kaybetmeyen para birimi olmuștur. Günümüzdeki Amerikan dolarının dolaşımı ve değerli oluşu gibi bu sikke tipi de antik dünya'da çok saygı görmüş̧ür.

Define sikkelerinin tipleri hiç değișmez ama arka yüz yazı lejandlarında üç farklı kralın adını görmekteyiz. Bunlar: Alexander III, Büyük (M.Ö. 336323), Philip III, Arrhidaios (M.Ö. 323-317) ve Seleukos I, Nikator (312-281)

${ }^{3}$ Merkholm (1991), sf. 47. 
olmaktadır. Görüldüğü üzere define sikkeleri, Makedonya kralı Büyük Alexander ile başlamakta ve onun ölümünden sonra kısa bir süre Makedonya kralı olan üvey kardeși, Philip III, Arrhidaeus ile devam etınekte ve Seleukos I, Nikator ile son bulmaktadır.

İskender'in çocukluk arkadaşı ve doğu seferinde hep yanında olan en yakın komutanlarından biri olan Seleukos, onun ölümünden sonra dörde bölünen büyük İskender İmparatorluğu topraklarının çok geniş doğu bölümünü (Anadolu'nun doğusundan başlayıp, Arap Yarımadası üst kısmı, İràı, Afganistan'ı da içine alan kara parçası) Makedonya Krallığının Babil satrabı olarak yönetmiştir. İskender'in öldüğü ve üvey kardeşi Philip III'ün tahtta çıktığı Babylon'dan ayrılıp, Makedonya'ya geçmesi ve daha sonra İskender'in annesi Olympias tarafından 317 yılında öldürülmesi üzerine Makedonya tahtında karışık bir dönem başlamıștır. Bir süre Babil'den uzaklaşıp, Baktria Satrabı olan Seleukos 312 yılında Babylon'u tekrar ele geçirmiş ve kendi adıyla tanıman Seleukos Krallığını kurmuştur. Birçok kaynak bu krallıktan Seleukos Krallığı veya Syria Krallığı olarak bahsetmektedir.

Definedeki sikkelerin en erken tarihli olanları, 336-323 tarihlerinden Amphipolis (kat. no. 1) ve 325-323 tarihlerinden Babylon (kat. no. 15-16) darplı olanlardır ki, bu üç sikke İskender'in yaşadığı dönemdendir. En geç tarihli sikkeler ise, 295 tarihli Seleukos I döneminden Seleukeia ad Tigrim baskılı (kat. no. 31-32) iki sikkedir. Philip Arrhidaeus'un iki sikkesi, 323-317 yılları arasından olup, Babylon darphanesinde (kat. no. 29-30) basılmışlardir.

Büyük İskender'in ilk sikkelerinde genetivus formda yalnızca İskender'in adı (A $\Lambda$ E $\Xi A N \triangle P O Y$ ) yazılıydı (bkz., kat. no. 1-13, 15-16, 28). Yaklaşıı 329 yılında Cilicia'nın Myriandrus (İskenderun) șehrinde basılan sikkelerde isminin yanma kral (BA $\mathrm{I} \Lambda \mathrm{E} \Omega \Sigma$ ) unvanı da eklendi ${ }^{4}$. O zamandan itibaren bu yeni yazı biçimi bazı bașka darphanelerce de benimsendi (bkz., burada kat. no. 14, 17-27, 29-32), fakat İskender'in yaşadığı süre içerisinde hiçbir zaman yaygınlık kazanmadı. Mısır'daki Ptolemaioslar'dan başlayarak, Diadokhlar, bastırdıkları sikkelerde hem unvan hem de isim kullandılar. Bu adet onların halefleri tarafından da sürdürüldü̈. Unvan sikkenin sağ boşluğuna ve isim ise Zeus'un oturduğu tahtın altına yerleştirilmiştir.

'Mçrkholm (1991), sf. 32; (bunun için blz.. H. Seyrig. 'Notes on Syrian Coins', NNM 19. NewYork, 1950).

5 a.g.y., sf. 32 . 
Arados ve Amathos 328 yılında bu yeni lejandı benimsemişlerdir. Fakat

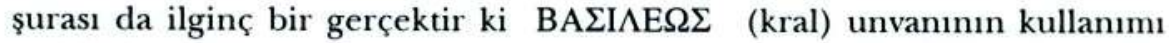
çeșitli darphanelerde yöneticilerin inisiyatifine bırakılmıștı. Büyük darphanelerden Amphipolis 325'te Babylon 324'te ve Tarsus 323'te unvanı benimsediler. Komşu darphaneler çoğu kez farkh uygulamalara gittiler; Pella, Damascus, Byblos, Sidon ve Ake gibi birkaç darphane unvanı İskender hayattayken asla kullanmadılar ${ }^{6}$.

İskender sikkelerinin arka yüzlerinde, isim ve unvanın dışında, çoğu kez kısaltılmış memur (magistrat) isimlerinin baş harfleri, monogramlar (iç içe geçmiş harfler), era senesini (bölgesel yıl) gösterir harf rakamları ve çeşitli simgeler yer almaktadır. Bazen darp yerine ilişkin ilk birkaç harften oluşan kısaltmalar veya monogramlar sikkenin hangi darphanede üretilmiş olduğu teşhisini kolaylaşturır. Örneğin Sidon'da basılmıș İskender ve Ptolemaios sikkelerindeki $\Sigma$ I ; Ptolemaiosların Kıbrıs'taki Salamis'te basılmıs sikkelerindeki $\Sigma$ A, Kition'da basılmış sikkelerinde KI ve Paphos'ta basılmış sikkelerindeki ПA gibi. Sikke boşluğuna yerleştirilmiş çeşitli nesnelerin, ufak resimlerinden oluşan ve ana tiple doğrudan ilişkisi bulunmayan yöresel simgeler de sikkenin basıldığı yeri teşhis etmede yardımcı olurlar. Örneğin Side'nin narı, Rodos'un gülü gibi simgeler sikkenin basıldığı darphaneyi bulmamızı kolaylaşurırlar. Bu türdeki sembolleri barındıran sikkeleri biz konuşan sikkeler olarak tanımlamaktayız. Bu tip sikkelere ilișkin iki örnek, Durmaz Definesi'nde de bulunmaktadır. Konuşan sikkeler için ilk örneğimizi 7 adet Carrhae sikkesi (bkz., kat. no. 5-11) oluşturmaktadır. Carrhae (Harran) sikkelerinin arka yüzünün sol boşluğunda bulunan hilâl (ay) sembolü, öteden beri bu şehirde ünlü Sin Tapınağını, dolayısıyla şehrin Ay Tanrısının kült merkezi olduğuna dair bir işarettir. Bu antik kent Ay Tanrısı Sin'in, daha sonraları adı Mên olan tanrının Mezopotamya'daki en önemli tapınım merkeziydi. Şehrin Roma dönemi sikkeleri üzerinde de yine yarımay (hilâl) betimlemesinin sıklıkla kullanılmış olduğunu görmekteyiz ${ }^{7}$. İkinci örneğimiz burada bir tek sikkesi olan Salamis'tir. Salamis sikkesinin (bkz., no. 4) arka yüzünde gemi dümeni betimlemesi bulunmaktadır ki, bu simge, liman kenti olan Salamis'in denizcilikteki ününün bir göstergesidir.

Hellenistik dönemde her bir darp serisinden doğrudan sorumlu olan yetkili memurları (magistratları) sikke üzerinde göstermek bir gelenek ha-

${ }^{6}$ a.g.y., sf. 36 .

${ }^{7}$ M. Arslan, 'Mezopotamya Bölgesi Şehir Sikkeleri', AMM 1996 Yılığı, Ankara 1997. 
line gelmiştir. Şehir magistratları (ki çoğu kez yıllık seçiliyordu) ve krali sikke basımından sorumlu memurlar, kontrolü altunda basılan sikkelere kendi adlarımı ya da adlarımın ilk birkaç harfini koyuyorlardı.

Sikke üzerindeki monogramlar ve sembollerde aynı şekilde bu memurlar tarafindan konuluyordu. Buradaki örneklerdeki gibi, krâli darplarda isim tam yazılmaz, ismin bir iki harfi veya monogram şeklindeki yazılıșı görülür. Müstakil şehir darplarında memurların isimleri tam, hatta soy isimleriyle birlikte yazılmaktaydı. Bazı sikkelerde darp yerini işaret eden kısaltma harfler, monogramlar ve simgeler olmadığı zaman, bilim adamı çeşitli sikke serilerinin analizini yapmakta çok zorlanmaktadır.

Sidon ve Ake'de basılan sikkeler üzerinde her yllın era tarihleri bulunduğu için biz bu sikkelerin ne zaman basıldıklarını kesin bir şekilde saptayabilmekteyiz. Örneğin bu definemizde bulunan iki Ake sikkesinden biri $314 / 3$ (kat. no. 13) ve diğeri 306/5 (kat. no. 14) tarihini taşımaktadır.

İskender sikkelerinin ön yüzündeki Herakles başı realistik (insana özgü) özellikler taşıdığından, birçok bilim adamı, sikkenin kalıbını hazırlayan sanatçımın gerçek niyetinin İskender'in idealize portresini resmetmek olduğunu varsaymaktadırlar. İskender'in hayatta iken basılan tetradrahmilerinden ziyade ölümünden sonra basılan hatura sikkelerinde bu durum daha belirgindir.

İskender drahmi ve tetradrahmilerinin arka yüzündeki Zeus'un tasvirlerinde zaman içinde iki farklı betimleme göze çarpar. Bazı serilerin basımlarında Zeus, taht üzerinde değil, arkalıksız bir sandalye (tabure) üzerinde oturur şekilde resmedilmiştir (bkz., kat. no. 1, 2, 3, 13,14). Bu tarzdaki Zeus betimlemelerinin, İskender'in hayatta iken basılan sikke serilerinden olduğunu düşünüyoruz. Çünkü kataloğumuzdaki en erken tarihli sikke betimlemelerinde Zeus, tahtta değil, bir tabure (kat. no. 1, 2) üzerinde oturmaktadır. Bu iki sikkemiz, İskender'in hayatta iken bastırmış olduğu sikkelerdendir. Fakat kataloğumuzun 3, 13 ve 14 numaralı sikkelerinde de Zeus tabure üzerinde oturur şekilde resmedilmiştir. Bu üç örnek, İskender'in ölümünden sonraki basımlar olup, 314, 310 ve 306 tarihli basımlardır. Sardes ve Ake darphanesine ait, bu üç örnekteki sikkelerimizin kalıp ustaları, İskender'in ölümünün üzerinden henüz 15,20 yıl geçmiş olmasına rağmen eski stildeki Zeus betimleme tipinden vazgeçememișlerdir. 
İskender paralarındaki ikinci bir farkh tasvir şekli, Zeus'un bacaklarına ilişkindir. Erken basımlarda bacaklar yan yana (paralel) șekilde dururken (kat. no. 1, 2, 15 ve 16), daha sonraki serilerde sağ bacak geride (kat. no. 314, 17-32) çapraz şekilde durmaktadır. Definemizde, Zeus'un bacaklarının paralel olarak tasvir edildiği sikkeler (no. 1, 2, 15 ve 16), İskender' in hayatta iken basılan en erken tarihli serilerindendir. Diğer 28 sikke ise, kesişen bacaklar serisinden olup, daha geç tarihlidirler.

Yaklaşık 326/5 yıllarında doğu'da iki darphane (Alexandreia ve Side) İskender Gümüş Sikkeleri basmaya bașladı. Mısır'daki Alexandreia çok güzel bir sikke serisi ile üretime başladı. Burada basılan tetradrahmilerin arka yüzündeki Zeus, kesişen bacakları ile daha esnek pozisyonda resmedilmiștir; ön yüzdeki Herakles başı da insani özellikler tașıdığından, birçok bilim adamı, sikkenin kalıbını hazırlayan sanatçının gerçek niyetinin İskender'in idealize portresini resmetmek olduğunu varsaymaktadır. Bu darphanenin yeni stili, diğer darphanelerce de taklit edildi: ilk önce 325/4'de Sidon, 323 'de Babylon ve 322/1'de Ake, Zeus'un bacaklarının kesişen pozisyonda resmedilmesini uygulamışlardır. Fakat, kesişen bacakların İskender imparatorluğunun tüm darphanelerinde benimsenmesi ve uygulanması $315 / 310$ tarihlerinden sonra olmuștur ${ }^{8}$.

\section{Durmaz Definesi'nde Bulunan Darphaneler}

1-) Amphipolis - Macedonia, kat. no. 1-2 = 2 adet

2-) Sardes - Lydia, kat. no. $3=1$ adet

3-) Salamis - Kıbris Adası, kat. no. $4=1$ adet

4-) Carrhae - Mesopotamia, kat. no. 5-11 = 7 adet

5-) Bilinmeyen Doğu veya Carrhae (?), kat. no. $12=1$ adet

6-) Ake - Phoenicia, kat. no. 13-14 = 2 adet

7-) Babylon - Babylonia, kat. no. 15-27 ve 29-30 $=15$ adet

8-) Ecbatana - Persia, kat. no. $28=1$ adet

9-) Seleuceia ad Tigrim - Babylonia, kat. no. 31-32 = 2 adet

\footnotetext{
${ }^{8}$ Merkholm (1991), sf. 56.
} 
Yukarıdaki listeden de anlașılacağı üzere, bu definemizde ismi bilinen sekiz ayrı darphane ve bilinmeyen bir darphanenin (liste 5, kat. no. 12) varlığı tespit edilmiştir. Darphane listesini batıdan doğuya doğru bir sıralamayla yaptık. Kataloğumuzda bu sıralama içinde verilmiştir.

Definemizdeki kalıp ilișkilerinin incelenmesi ancak, iki darphanenin sikkeleri üzerinde mümkün olmaktadır. Çünkü definede aynı tarihlerden olan yalnız iki darphane sikkeleri çoğunluk olarak bulunmaktadır. Bu iki darphane, Babylon ve Carrhae darphaneleridir. 7 sikkesi olan Carrhae'nin 6, 7 ve 8 numaralı sikkelerinin önyüz kalıpları aynıdır. 9 numaralı sikkenin de, bu üç sikkedeki ön yüzlerin kalıbından üretilmiş olması mümkündür. Arka yüz kalıplarının hepsi farklı olmakla beraber, 7 ve 9 numaralı sikkeler, kesin olmamakla beraber aymı kalıptan üretilmiş olabilir.

Babylon darphanesinin 15 sikkesinden 13'ü İskender'in adım (kat. no. 15-27) ve 2 sikke Philip III'ün adına basılmışlardır. Ancak hiçbirinin ön yüz ve arka yüzleri aymı kalıptan üretilmemiștir. Diğer 7 darphanenin basımları bir ve nadiren iki sikke ile sınırlıdır. Bu yüzden kalıp ilişkileri açısından incelenmesinin bir anlamı olmaz. Zaten bunların hiçbirinin kalıp benzerlikleri de bulunmamaktadır.

\section{İskender'in Yaşadığı Sürede Sikkesini Basmış Olan Darphanelerin}

\section{Listesi}

1-) Amphipolis-Makedonya

2-) Aigai-Makedonya

3-) Pella-Makedonya

4-) Lampsakos-Mysia

5-) Abydos-Troas

6-) Kolophon-İonia

7-) Magnesia-İonia

8-) Miletos-İonia

9-) Sardes-Lydia

10-) Side-Pamphylia 
11-) Tarsos-Kilikia

12-) Myriandros-Kilikia

13-) Amathos-Kıbris

14-) Kition-Kıbris

15-) Paphos-Kıbris

16-) Salamis-Kıbris

17-) Damaskos-Syria

18-) Hierapolis-Syria

19-) Ake-Finike

20-) Byblos-Finike

21-) Karne-Finike

22-) Marathos-Finike

23-) Sidon-Finike

24-) Babylon-Babylonia

25-) Susa-Susiana (Persia)

26-) Memphis-Misır

27-) Alexandria-Mısır

Yukarıda görüldüğü üzere İskender hayattayken 27 kent darphanesinde sikkelerinin bastırılmış olduğu tespit edilebilmiştir. Bunlardan Makedonya'daki üç darphane (Amphipolis, Pella ve Aigai) babası tarafından kurulmuştu. Pella İskender krallığının başkenti, Amphipolis ise en büyük ticaret merkezi konumunda olduğu için en çok sikke basturan bir darphane hüviyetini Babylon ile birlikte sürdürmüştür. Aigai kenti dini bir merkez olup, birkaç tetradrahmi örneğinin dışında daha çok altın para bastırmıştur. Bu darphanelerden Anadolu'nun batısındaki Lampsakos, Abydos, Kolophon, Miletos ve Sardes gibi darphaneler başlangıçta drahmi basmıșlar, sonra tetradrahmi'ye geçmişlerdir. Suriye'deki Hierapolis ise, tek bir tetradrahmi örneğiyle tanınmaktdır. 
Antik dünyada İskender drahmileri ve tetradrahmileri basmış darphanelerin sayısı bugüne kadar 100 civarında tespit edilmiștir. Bu sayıya ismi bilinmeyen darphaneler dahil değildir. Bunlar her coğrafi bölgede bulunmaktadır. Bu tür definelerin buluntularının yayımlanmasıyla bu problemlerin çözümü daha da kolaylaşacaktur. Biz burada İskender drahmisi ve tetradrahmisini basmıș tüm darphanelerin bir listesini vermedik. Sadece yukarıda onun yaşadığı dönemde sikke bastırmıs olduğu darphanelerin bir listesini verdik. Ölümünden sonra onun adıyla sikkesini bastırmıs diğer 73 ve bu listedekilerde dahil tüm darphanelerini gösterir haritaları burada yayımlamaktayız (bkz., haritalar: 1-6). Böylece ilgilenen kişilerin hangi antik coğrafi bölgede, hangi șehrin İskender sikkesi basmış olduğunu öğrenmesi ve akılda tutması daha kolay olacaktur.

Antakya civarında bulunduğu söylenen bu definenin, 200 kadar sikkeden oluștuğunun söylenmiş olmasına karşılık, ancak 32 adetinin toplu olarak 1992 yılında Sn. Mehmet Durmaz tarafından satın alınmış olduğunu bilmekteyiz. Define, bölünmüş olsa bile, bu haliyle, Büyük İskender'in para politikasının detaylarımı ve onun ardından gelen krallarca da bu politikanın büyük ölçüde sürdürülmüş olduğunu bu define sayesinde bir kez daha görmekteyiz.

Sonuç olarak bu define sikkeleri İskender'in yaşadığı zamandan (336323) başlayıp, onun ölümünden kısa bir süre sonrasında da (30-40 yıl) tedavülde kalmıș sikkelerden oluşmaktadır. En son tarihli sikkemiz 295 yılına tarihlendiğine göre, bu define 290 yillarında, yani Seleukos I (312-281) henüz iktidarda iken toprağa gömülmüș olmalıdır.

\section{Katalog ve Metin İçinde Geçen Kısaltmalar:}

$\begin{array}{ll}\text { a.g.y. } & \text { : adı geçen yayın } \\ \text { mong. } & : \text { monogram } \\ \text { mongrl } & : \text { monogramlar } \\ \langle S B\rangle & : \text { Sol Boşlukta } \\ \langle T A\rangle & : \text { Taht (tabure) Altında }\end{array}$




\section{SEÇILMIŞ FAYDALI KAYNAKÇA ve KISALTMALARI}

\section{Afyon (1976) \\ Ain-Tab \\ AJN \\ Akçakale}

Akkar

Aleppo (1893)

Aleppo (1930)

ANS

ANSMN

Armenak

Asia Minor (1964)

Asia Minor (1973/4)

Babylon (1900)

Babylon (1973)

Bataşani

BMC Arabia, etc.
Afyon Hoard, before 1976: $C H 3$ (1977), no. 30

Ain-Tab (Aintab) hoard: $I G C H$ 1542; references to seyrig, Trésors, no.13

American Journal of Numismatic

Akçakale hoard: G. L. Rider and N. Olcay, "Un trésor de tétradrachmes d'Alexandre trouvé à Akçakale en 1958", $R N$ 1988: 42-54, pl. v-x.

Akkar hoard: IGCH 1559; references to Seyrig, Trésors, no.18

Aleppo hoard, 1893: IGCH 1516

Aleppo hoard, 1930: IGCH 1562

The American Numismatic Society, New York

American Numismatic Society, Museum Notes

Armenak hoard: IGCH 1423; references to M. Thompson, The "Armenak" hoard (IGCH 1423), ANSMN 31 (1986): 63-106, pl. vi-xxvi

Asia Minor hoard, 1964: IGCH 1437

Asia Minor hoard, 1973/4: $C H 1$ (1975), no. 56

Babylon hoard, 1900: IGCH 1774; references to K. Regling, "Hellenistischer Münzschatz aus Babylon", ZFN 38 (1928):92-132, pl. viii-xiii

Babylon (Mashtal, Baghdad) hoard, 1973: $\mathrm{CH} 4$ (1973), no. 33

Bataşani hoard: $\mathrm{CH} 2$ (1976), no. 65

G. F. Hill, Arabia, Mesopotomia and Persia (Nabataea, Arabia Provincia, South Arabia, Mesopotamia, Babylonia, Assyria, Persia, Alexandrine Empire of the East, Persis, Elymais, Characene), London, 1922 (Catalogue of Grek Coins in the Brirish Museum)

BMC Cyprus $\quad$ G. F. Hill, Cyprus, London, 1901 (Catalogue of Grek Coins in the Brirish Museum) 
$\mathrm{CH}$

Demanhur

Diyarbakir (1955)

Ehrhardt, Amphipolis

Gordion V (1961)

Haymana

$I G C H$

JHS

JIAN

JNFA

$J N G$

Kirazh

Kirikhan

Larnaca

Latakia (1759)
Coins Hoards

Demanhur hoard: IGCH 1664; references to E. T. Newell, "Alexander Hoards II, Demanhur", 1905, New York, 1923 (NNM 19)

Ayrıca șurada: O. Zarvos, "Additions to the Demanhur hoard of Alaxander tetradrachms", NC 1980: 185-188

Diyarbakir (Diyarbekir) hoard, 1955: IGCH 1735; (1975), references to Seyrig, Trésors, no.4

C. Ehrhardt, "A catalogue of issues of tetradrachms from Amphipolis, 318-294 BC", JNFA 4 (1976): 85-89 Gordion V hoard, 1961: IGCH 1405; references to D. H. Cox, "Gordion hoards III, IV, V, and VII ANSMN 12 (1966): 19-55, pl. iii-xxi, at 33-51

Haymana hoard: G. L. Rider and N. Olcay, "Le trésor de Haymana", $R N$ 1988: 55-63, pl. xi

M. Thompson, O. Mִ̨rkholm and C. M. Kraay (eds), Inventory of Grek Coin Hoards, New York, 1973

Journal of Hellenic Studies

Journal International d'Archélogie Numismatique

Journal of Numismatique Fine Arts

Jahrbuch für Numismatik und Geldgeschichte

Kirazh hoard: IGCH 1369; references to G. Le Rider and N. Olcay, 'Le trésor de Kirazlı (prés de d'Amasya): IGCH 1369', Anatolia Antiqua/Eski Anadolu, Recueil de Travaux publiés par IIstitut français d'Études Anatoliennes d'Istanbul (ed. B. Rémy), İstanbul/Paris, 1987 (Varia Anatolica 1)

Kirikhan hoard: $C H 1$ (1975), no. 87A and 87B; references to Seyrig, Trésor, no. 23 ('Cilicie')

Larnaca hoard: IGCH 1472; references to Price, 'Greek coin hoards', 4-8

Latakia hoard, 1759: IGCH 1544; references to seyrig, Trésor, no. 11 
Kuft

\section{Meydancikkale}

Mđcrkholm (1991)

Mosul (1862-3)

Müler

Mylasa

$N C$

Newell, 'Ake'

Newell, 'Cypriote'

Newell, 'Demenhur'

Newell, ESM

Newell, WSM
Kuft hoard: IGCH 1670; D. Nash, "The kuft hoard of Alexander III tetradrachms", NC 1974, 14-30; O. Zervos, "Newell's manuscript of the Kuft hoard", ANSMN 25 (1980): 17-90, pl. iii

Meydancıkkale (Gülnar) CH 7 (1985), no. 80 A. Davesne - G. Le Rider, Le Trésor de Meydancıkkale (Cilicie Tracée, 1980), Paris 1989 (Institut français d'Études Anatoliennes, Gülnar 2)

O. Mфrkholm, Early Hellenistic Coinage from the Accession of Alexander to the Peace of Apamea (336-188 B.C.) Edited by. P. Grierson and U. Westermark, Cambridge/New York 1991; aynı eser için bkz., "Erken Helenistik Çağ Sikkeleri Büyük İskender'in tahta çıkışından Apameia Barışı'na kadar (İ.Ö. 336-188)" [çeviri: Oğuz Tekin] Homer Kitapevi, İstanbul 2000

Mosul hoard, 1862-3(?):IGCH 1756

L. Müller, Nümismatique d'Alexander le Grand, suivi d'un appendice contenant es monnaies de Philip II et III, Copenhagen, 1855

Mylasa hoard: IGCH 1289

Numismatic Chronicle

E. T. Newell, The Dated Alexander Coinage of Sidon and Ake, New Haven/Oxford, 1916 (Yale Oriental Series; Researches 2): 7-38, pl. i-v.

E. T. Newell, "Some Cypriote Alexanders, 'Salamis' at 306-316, pl. xiii-xv.

E. T. Newell, Alexander Hoards II. Demenhur, 1905, New York, 1923 (NNM 19)

E. T. Newell, The Coinage of the Eastern Seleucid Mints from Seleucus I to Antiochus III, New York, 1938 (ANS Numismatica Studies 1)

E. T. Newell, The Coinage of the Western Seleucid Mints from Seleucus I to Antiochus III, New York, 1941 (ANS Numismatica Studies 4): 37-43 
Newell,

NNM

Oylum (1993)

Price (1991)

Prokesch-Osten (1)

Prokesch-Osten (2)

Seyrig (1950)

SNG Cop

SNR

Susa II $(1948 / 9)$

Susa V (1933/4)

Susiana (1965)
Reatribution E. T. Newell, "Reattribution of certain tetradrachms of Alexander the Great ",New York, 1912

Numismatic Notes and Monographys, New York (ANS)

E. Özgen et A. Davesne, 'Le Trésor de Oylum Höyüğü', Trésor et circulation monétaire en Anatolie antique, (ed. M. Amandry - G. Le Rider), Paris 1994: 45-59

M. J. Price, The Coinage in the Name of Alexander the Great and Philip

Arrhidaeus: A British Museum Catalogue (London/Zurich, 1991)

[A.] von Prokesch-Osten, 'Liste des Alexandres de ma colection qui ne se trouvent pas dans le catalogue de Mr. L. Müller', NZ 1 (1869[1870]), 31-64

[A.] von Prokesch-Osten, 'Suite des monnaies inédites d'or et d'argent d'Alexandre le Grand', $N Z$ 3 (1871 [1873]), 51-72

H. Seyrig, 'Notes on Syrian Coins', NNM 119, NewYork, 1950

Sylloge Nummorum Graecorum. The Royal Collection of Coins and Medals, Danish National Museum [9] Mecedonia 2: Alexander I-Alexander III, Copenhagen, 1943 (nos. 478-1066)

Schweizerische Numismatische Rundschau

Susa II hoard, 1948/9: IGCH 1799; references to Le Rider, Suse, 243-4

Susa V hoard, 1933/4: IGCH 1804; references to Le Rider, Suse, 246-8

Susiana hoard, 1965: IGCH 1806; references to A. Houghton and G. L. Rider, 'Un trésor de monnaies hellénistiques trouvé près de Suse', RN 1967, 111127, pl. iv-x 
Syria (1959)

Syria (1960)

Tarik Darreh

Tell Halaf

Tell Kotchek

Turkey (1973/4)

Thompson 'Sardes'

Urfa

Winterthur

Woggoner 'Babylon'

Woggoner 'Seleucia'
Syria hoard, 1959: IGCH 1535; references to Boehringer, Chronologie, 158-61

Syria hoard, 1960: IGCH 1533; references to Seyrig, Trésor, no. 3

Tarik Darreh hoard: : $C H 7$ (1985), no. 78; references A. Houghton, 'Tarik Darreh (Kangavar) hoard', ANSMN 25 (1980), 31-44, pl. iv-v

Tell Halaf hoard: $I G C H 11763$

Tell Kotchek hoard: $I G C H$ 1773; references to Seyrig, Trésor, no. 15

Turkey hoard, 1973/4: $\mathrm{CH} 1$ (1975) no. 56

M. Thompson, Alexander's Drachm Mints, 1. Sardes and Miletus, New York, 1983 (ANS Numismatic Studies 16), Sardes at 5-42, pl. i-xx

Urfa hoard: $I G C H$ 1772; references to Price, 'Greek coin hoards', 10-4, pl. iv

H. Bloesch, Griechische Münzen in Winterthur, 1. Spanien, Gallien, Italien, Moesien, Dakien, Sarmatien, Thrakien, Makedonien, Hellas, Inseln, Winterthur, 1987

N. M. Woggener, The Alexander mint at Babylon (Doctoral Dissertation, Columbia University, 1968)

N. M. Woggener, "The early Alexander coinage at Seleucia ad Tigrim", ANSMN 15 (1969): 21-30, pl. iiiv.

Zeitschrift für Numismatik 


\section{KATALOG}

\section{ALEXANDER III, Büyük (M.Ö. 336-323)}

Ön yüz:

Arka yüz:

1. Arka yüz

Env. No.

Ölç/Ağr $/ Y$ Yön

Ref.

2. Arka yüz

Env. No.

Ölç/Ağr/Yön

Ref.
Herakles bașı sağa; aslan postundan bir bașlık giymiș. Noktalı bordür.

Zeus tahtta sola oturuyor, belden yukarısı çıplak, sağ elinde kartal, sol elinde uzun asa tutuyor. Noktalı bordür.

A $\Lambda E \Xi A N \triangle P O Y$ yazısı sağ boșlukta, bazı sikkelerde, BA $\Sigma I \Lambda E \Omega \Sigma$ A $\Lambda$ E $\Xi A N \triangle P O Y$

şeklinde sağda ve altta devam etmektedir.

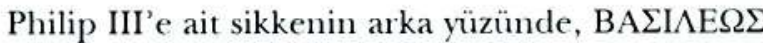
ФІ ІППОҮ ve Seleukos I'in sikkesinde, BAEI$\Lambda E \Omega \Sigma \Sigma E \Lambda E Y K O Y$ yazısı okunmaktadir.

Not: Sikkelerin arka yüzlerinde, genellikle sol boşlukta ve Zeus'un oturduğu taburenin altunda olmak üzere değișen monogram ve semboller bulunmaktadır. Bunlanı katalog içinde sol boşlukta $\langle\mathrm{SB}\rangle$ ve tabure altunda $\langle\mathrm{TA}\rangle$ şeklinde göstermekteyiz.

\section{Amphipolis-Macedonia darphanesi}

(M.Ö. 336-323)

$A \wedge E \Xi A N \triangle P O Y$

$<S B>$ herme heykelciği sola

36

$17.04 \mathrm{gr} ; 28 \mathrm{~mm} .1 \mathrm{~h}$.

Price, 78; Demanhur, 716-791; SNG Cop., 676;

Newell, 'Reattribution', 30

\section{A $\Lambda$ EEAN $\triangle \mathrm{POY}$}

$<S B>$ aplustre; $\langle T A>$ mong.: ๆ

37

$17.38 \mathrm{gr} ; 25 \mathrm{~mm} .9 \mathrm{~h}$.

Price, 129; SNG Cop., 676; Ehrhardt, 'Amphipolis', 13 
Sardes-Lydia darphanesi (M.Ö. 315-300)

3. Arka yüz A $\triangle$ E $\Xi A N \triangle P O Y$

$<S B>$ mong.: $(\mathbb{D}<T A>$ mong.: $\mid \mathcal{V}$

Env. No.

39

Ölç/Ağr/Yön

$16.88 \mathrm{gr} ; 26 \mathrm{~mm} .12 \mathrm{~h}$.

Ref.

Price, 2681 (drahmi); Thompson, 'Sardes' 396b (drahmi)

Not. Bu arka yüz kalıbı tetradrahmi için yeni olup, bir drahmi dışında șimdiye kadar tanınmıyordu.

Salamis-Kıbris darphanesi (M.Ö. 310-302)

4. Arka yüz A $\Lambda$ EEAN $\triangle P O Y$

$<S B>$ gemi dümeni ve üzüm salkımı; mong.: Ф

$<T A>$ mong.: ${ }^{\mathrm{E}}$

Env. No.

34

Ölç/Ağr/Yön $16.92 \mathrm{gr} ; 26 \mathrm{~mm} .12 \mathrm{~h}$.

Ref.

Price, 3164; Newell, 'Salamis' 23.

\section{Carrhae-Mesopotamia darphanesi} (M.Ö. 305-300)

5. Arka yüz

[B]A $\Sigma \mathrm{I} \Lambda \mathrm{E}[\Omega \Sigma]$ A $\Lambda \mathrm{E} \Xi \mathrm{AN} \Delta \mathrm{POY}$

$<S B>$ hilâl ve $\Theta E$; $<T A>$ mong.:

Env. No. $\quad 16$

Ölç/Ağr/Yön $16.97 \mathrm{gr} ; 26 \mathrm{~mm}$. 3h.

Ref.

Price, 3813; Müller, 268; Meydancıkkale, 1957;

Newell, WSM 40.4.

6. Arka yüz

[BA] $\Sigma[\mathrm{I} \Lambda \mathrm{E} \Omega \Sigma][\mathrm{A}] \Lambda \mathrm{E} \Xi \mathrm{AN} \Delta[\mathrm{POY}]$

$<S B>$ hilâl ve $\Delta \mathrm{I}$; $<T A>$ mong.:

Env. No. 14

Ölৎ̧/Ağr/Yön $17.11 \mathrm{gr} ; 26 \mathrm{~mm}$. $6 \mathrm{~h}$. 
Ref.

Price, 3818; Müler, 267; Meydancıkkale, 1958-60;

SNG Cop. 851;

Newell, WSM 41.9.

7. Arka yüz

[BA $\Sigma \mathrm{I}] \Lambda \mathrm{E} \Omega[\Sigma][\mathrm{A} \Lambda \mathrm{E}] \Xi \mathrm{AN} \Delta[\mathrm{POY}]$

$<S B>$ hilâl ve $\Delta \mathrm{I} ;\langle T A>$ mong.:

Env. No.

15

Ölç/Ağr $/ Y o ̈ n$

Ref.

$16.89 \mathrm{gr} ; 25 \mathrm{~mm} .6 \mathrm{~h}$.

Price, 3818; Müller, 267; Meydancıkkale, 1958-60;

SNG Cop. 851;

Newell, WSM 41.9.

8. Arka yüz

$[\mathrm{BA}] \Sigma \mathrm{I} \Lambda \mathrm{E} \Omega[\Sigma]$ A $\Lambda \mathrm{E} \Xi \mathrm{AN} \Delta \mathrm{POY}$

$<S B>$ hilâl ve $\Delta \mathrm{I} ;<T A>$ mong.:

Env. No. $\quad 12$

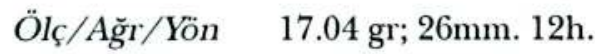

Ref.

Price, 3818; Müller, 267; Meydancıkkale, 1958-60;

SNG Cop. 851;

Newell, WSM 41.9.

9. Arka yüz

[BA] $\Sigma \mathrm{I} \Lambda \mathrm{E}[\Omega \Sigma][\mathrm{A} \Lambda \mathrm{E} \Xi \mathrm{AN} \Delta \mathrm{POY}]$

$<S B>$ hilâl ve $\Delta \mathrm{I} ;<T A>$ mong.: (8)

Env. No.

13

Ölç/Ağr $/ Y o ̈ n$

$16.85 \mathrm{gr} ; 26 \mathrm{~mm} .3 \mathrm{~h}$.

Ref.

Price, 3818; Müller, 267; Meydancıkkale, 1958-60;

SNG Cop. 851;

Newell, WSM 41.9.

10. Arka yüz

$\mathrm{BA} \Sigma \mathrm{I} \Lambda[\mathrm{E} \Omega \Sigma]$ [A $\Lambda \mathrm{E} \Xi \mathrm{AN} \triangle \mathrm{POY}]$

$<S B>$ hilâl ve $\Delta \mathrm{IO} ;<T A>$ mong.:

Env. No. $\quad 17$

Ölç/AğT $/$ Yön $16.93 \mathrm{gr} ; 26 \mathrm{~mm}$. 9h.

Ref.

Price, 3818A; Winterthur, 1506.

11. Arka yüz
$\mathrm{BA} \Sigma \mathrm{I} \Lambda \mathrm{E} \Omega[\Sigma]$ A $\Lambda \mathrm{E} \Xi \mathrm{AN} \Delta \mathrm{POY}$

$<S B>$ hilâl ve mong.: $\quad ;<T A>$ mong.: 
$\begin{array}{ll}\text { Env. No. } & 18 \\ \text { Ölç/Ağr/Yön } & 16.98 \mathrm{gr} ; 27 \mathrm{~mm} .9 \mathrm{~h} . \\ \text { Ref. } & \text { Price, 3820; Müller, 269; Newell, WSM 41.11. }\end{array}$

Bilinmeyen Doğu veya Carrhae (?)

(M.Ö. 300)

12. Arka yüz

BA $I \Lambda E[\Omega \Sigma]$ А $\Lambda E \Xi A N \triangle P[O Y]$

$<S B>$ mong.: $\mathbb{N}<T A>\mathrm{I} \Delta$

Env. No. $\quad 40$

Ölç/Ağr/Yön $16.87 \mathrm{gr} ; 26 \mathrm{~mm} .12 \mathrm{~h}$.

Ref. Not: Bu tip şimdiye kadar yayınlanmamıştır. Carrhae olduğu kesin değildir ve krâli monogramlar taşımaktadır.

Ake -Phoenicia darphanesi (M.Ö. 314/4)

13. Arka yüz A $\Lambda$ E $\Xi A N \triangle P O Y$

$<S B>$ aramice era : III « † $(=33=314 / 3$ yılı $)$

Env. No. $\quad 38$

Ölç/Ağr/Yön $17.06 \mathrm{gr} ; 27 \mathrm{~mm} .9 \mathrm{~h}$.

Ref. Price, 3286; Newell Ake, 37

Ake (M.Ö. 306/5)

14. Arka yüz [BA $\Sigma$ I $] \Lambda$ E $\Omega \Sigma]$ A $\Lambda$ EEAN $\Delta P O Y$

$<S B>$ era yılı: $-\dashv O{ }_{(=\text {yil } 33=306 / 5)}$

Env. No. 11

Ölç/Ağr $/$ Yön $16.94 \mathrm{gr} ; 28 \mathrm{~mm} .6 \mathrm{~h}$.

Ref. Price, 3301; Newell Ake, 50

Babylon -Babylonia darphanesi

(M.Ö. 325-323)

15. Arka yüz A $\triangle \mathrm{E} \Xi \mathrm{AN} \Delta \mathrm{POY}$

$<S B>$ meşale; $<T A>$ mong.: $\mid \hat{N}$ 
Env. No. 31

Ölç/Ağr/Yön $16.92 \mathrm{gr} ; 27 \mathrm{~mm} .11 \mathrm{~h}$.

Ref.

16. Arka yüz Price, 3643; Müller, 704; Demanhur, 4144 [A $\Lambda$ E $\Xi A N \Delta]$ POY $<S B>$ caduceus; $<T A>$ mong.: $\mid W$

Env. No. 32

Ölç/Ağr $/$ Yön $16.86 \mathrm{gr} ; 27 \mathrm{~mm} .3 \mathrm{~h}$.

Ref. Price, 3682; Demanhur, 4461

Babylon (M.Ö. 323-317)

17. Arka yüz $\mathrm{BA} \Sigma \mathrm{I} \Lambda \mathrm{E} \Omega[\Sigma]$ A $\Lambda$ E $\Xi \mathrm{AN} \triangle \mathrm{POY}$ $<S B>M ;<T A>\Lambda Y$

Env. No. 23

Öl $/$ /Ağr $/ Y \ddot{n} \quad 16.89 \mathrm{gr} ; 28 \mathrm{~mm}$. 3h.

Ref. Price, 3692; Müller, 1272; Demanhur, 44794525; Newell, 'Reattribution' 244

18. Arka yüz

\section{$\mathrm{BA} \Sigma \mathrm{I} \Lambda \mathrm{E} \Omega \Sigma$ A $\Lambda \mathrm{E} \Xi \mathrm{AN} \triangle \mathrm{POY}$}

$<S B>\mathbf{M} ;<T A>\Lambda \mathrm{Y}$

Env. No.

24

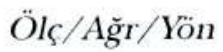

$16.95 \mathrm{gr} ; 27 \mathrm{~mm} .6 \mathrm{~h}$.

Ref.

Price, 3692; Müller, 1272; Demanhur, 4479-4525

\section{Babylon (M.Ö. 317-311)}

19. Arka yüz BA I $\Lambda$ E $\Omega \Sigma[\mathrm{A}] \Lambda \mathrm{E} \Xi \mathrm{AN} \triangle \mathrm{POY}$ $<S B>$ çelenk içinde mong.: $P$ P $<T A>\mathrm{H}$

Env. No. $\quad 19$

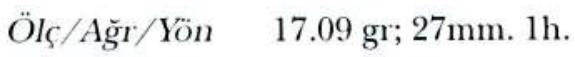

Ref. Price, 3704; Müller, 714; Armenak, 135 
20. Arka yüz

[BA $\Sigma] \mathrm{I} \Lambda \mathrm{E} \Omega[\Sigma] \mathrm{A} \Lambda \mathrm{E} \Xi \mathrm{AN} \Delta \mathrm{POY}$

Env. No.

$<S B>$ çelenk içinde mong.: $M P<T A>\mathrm{H}$

Ölç/Ağr /Yön 20

Ref.

$17.01 \mathrm{gr} ; 26 \mathrm{~mm} .12 \mathrm{~h}$.

Price, 3704; Müller, 714; Armenak, 135

21. Arka yüz

[BA $\Sigma \mathrm{I} \Lambda \mathrm{E} \Omega \Sigma$ A $\Lambda$ E $\Xi \mathrm{AN} \Delta \mathrm{POY}]$ $<S B>\mathrm{H} ;<T A>$ çelenk içinde mong.: $\mathrm{P}$

Env. No. 30

Ölç/Ağr/Yön $16.86 \mathrm{gr} ; 26 \mathrm{~mm} .12 \mathrm{~h}$.

Ref.

Price, 3708; Müller, 713; Armenak, 3

22. Arka yüz

Env. No.

[BA] $\Sigma \mathrm{I} \Lambda \mathrm{E} \Omega \Sigma$ A $\Lambda$ E $\Xi A N \triangle \mathrm{POY}$ $<S B>$ çelenk içinde mong.: $M{ }<T A>\mathrm{K} \Lambda$

Ölç/Ağr $/ Y o ̈ n$ 21

Ref.

$17.04 \mathrm{gr} ; 28 \mathrm{~mm}$. $3 \mathrm{~h}$.

Price, 3708; Müller, 717

23. Arka yüz

$\mathrm{BA} \Sigma[\mathrm{I} \Lambda \mathrm{E} \Omega \Sigma] \mathrm{A} \Lambda \mathrm{E} \Xi \mathrm{AN} \Delta \mathrm{POY}$

$<S B>$ çelenk içinde, $M P$ PTA $>$ mong.: $X$

Env. No. 33

Ölç/Ağr /Yön

17.02 gr; $27 \mathrm{~mm}$. $5 \mathrm{~h}$.

Ref.

Price, 3722-23; Müller, 727;

Prokesch-Osten (1), 130

24. Arka yüz

$\mathrm{BA} \Sigma \mathrm{I} \Lambda \mathrm{E} \Omega[\Sigma][\mathrm{A} \Lambda \mathrm{E}] \Xi \mathrm{AN} \Delta \mathrm{POY}$

Env. No.

$<S B>$ mong.: $X<T A>$ çelenk içinde, $M P$

Ölç/Ağr $/ Y o ̈ n$

27

Ref.

$16.92 \mathrm{gr} ; 27 \mathrm{~mm}$. 3h.

Price, 3725; Müller, 728

Babylon (M.Ö. 311-305)

25. Arka yüz

[BA $\Sigma \mathrm{I}] \Lambda \mathrm{E} \Omega[\Sigma] \quad[\mathrm{A} \Lambda \mathrm{E}] \Xi \mathrm{AN} \Delta \mathrm{P}[\mathrm{OY}]$ $<S B>$ çelenk içinde mong.: $M$

Env. No. 22

Ölç/Ağr/Yön $17.07 \mathrm{gr} ; 27 \mathrm{~mm}$. 3h. 
Ref. Price, 3746; Müller, 734; Armenak, 1367-7; Prokesch-Osten (1), 134

26. Arka yüz

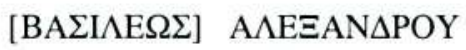

$<S B>\mathrm{MI} ;<T A>$ çelenk içinde mong.: $M$

Env. No. $\quad 28$

Ölç/Ağr $/$ Yön $17.03 \mathrm{gr} ; 25 \mathrm{~mm} .6 \mathrm{~h}$.

Ref. Price, 3751; Müller, 735; Armenak, 138-9

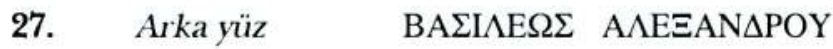

$<S B>$ MI ve Herakles sopası

$<T A>$ çelenk içinde mong.: $A$

Env. No. $\quad 29$

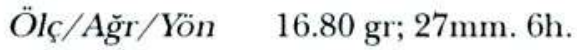

Ref. $\quad$ Price, 3765; Müller, 739; Armenak, 142;

SNG Cop, 837

Ecbatana - Persia darphanesi

(M.Ö. 311-295)

28. Arka yüz

A $\Lambda$ E]EAN $\triangle \mathrm{POY}$

$<S B>$ mongrl.: $\frac{\nabla}{<}$ gemi çapası ve

otlayan at;

$<T A>\Sigma \Omega$

Env. No. $\quad 35$

Ölç/Ağr/Yön $16.99 \mathrm{gr} ; 28 \mathrm{~mm} .6 \mathrm{~h}$.

Ref. Price, 3931; Newell ESM, 475

PHILIP III, Arrhidaeus (M.Ö. 323-317)

Babylon - Babylonia (323-317)

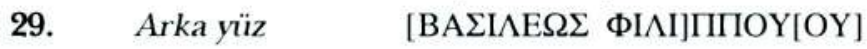

$<S B>M ;<T A>B$

Env. No. $\quad 26$

Ölç/Ağr $/$ Yön $16.92 \mathrm{gr} ; 27 \mathrm{~mm} .12 \mathrm{~h}$. 
Ref.

30. Arka yüz

Env. No.

Ölç/Ağr/Yön

Ref.

32. Arka yüz

Env. No.

Ölç/Ağr/Yön

Ref.

31. Arka yüz

Ref.
Price, P182; Müller, 103; Demanhur, 4601; Newell 'Reattribution', 241

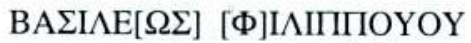

$<S B>\mathrm{M} ;<T A>$ mong.:

25

$14.68 \mathrm{gr} ; 26 \mathrm{~mm}$. 3h.

Price, P186; Müller, P103; Demanhur, 4595-4600

SELEUKOS I, Nikator (M.Ö. 312-280)

Seleukeia ad Tigrim- Babylonia (M.Ö. 295)

BA $\Sigma \mathrm{I} \Lambda \mathrm{E} \Omega[\Sigma] \Sigma \mathrm{E} \Lambda \mathrm{EYKOY}$

$<S B>$ mong.: $\mathcal{A}<T A \Delta \mathrm{I}$

Env. No. 41

Ölç/Ağr/Yön $16.89 \mathrm{gr} ; 27 \mathrm{~mm} .1 \mathrm{~h}$.

Price, 3784 (?); SNG Cop, 848 (?)

\section{BA $\Sigma \mathrm{I} \Lambda \mathrm{E} \Omega[\Sigma] \Sigma \mathrm{E} \Lambda \mathrm{EYKOY}$}

$<S B>$ mong.: $\Re_{<T A}[\Delta \mathrm{I}$ ?]

42

$16.80 \mathrm{gr} ; 27 \mathrm{~mm} .11 \mathrm{~h}$.

Price, 3784 (?); SNG Cop, 848 (?)

Not: Bu iki Selevkos sikkesi şimdiye kadar bilinmeyen kalıp varyasyonları olup, benzer çeşitler $\mathrm{Ne}$ well $^{9}$ ve Waggoner ${ }^{10}$ tarafindan yayınlamıștır. Bu iki sikke kralın kendi adıyla bastırmış olduğu ilk serilerden olmalıdır.

$(8)$
$(8)$
A

${ }^{9}$ E. T. Newell, The Coinage of the Eastern Seleucid Mints, p. 12.4.

${ }^{10}$ N. M. Waggoner, 'The early Alexander coinage at Seleucia on the Tigris', ANSMN 15 (1969), p. 21-31. 
Melih Arslan

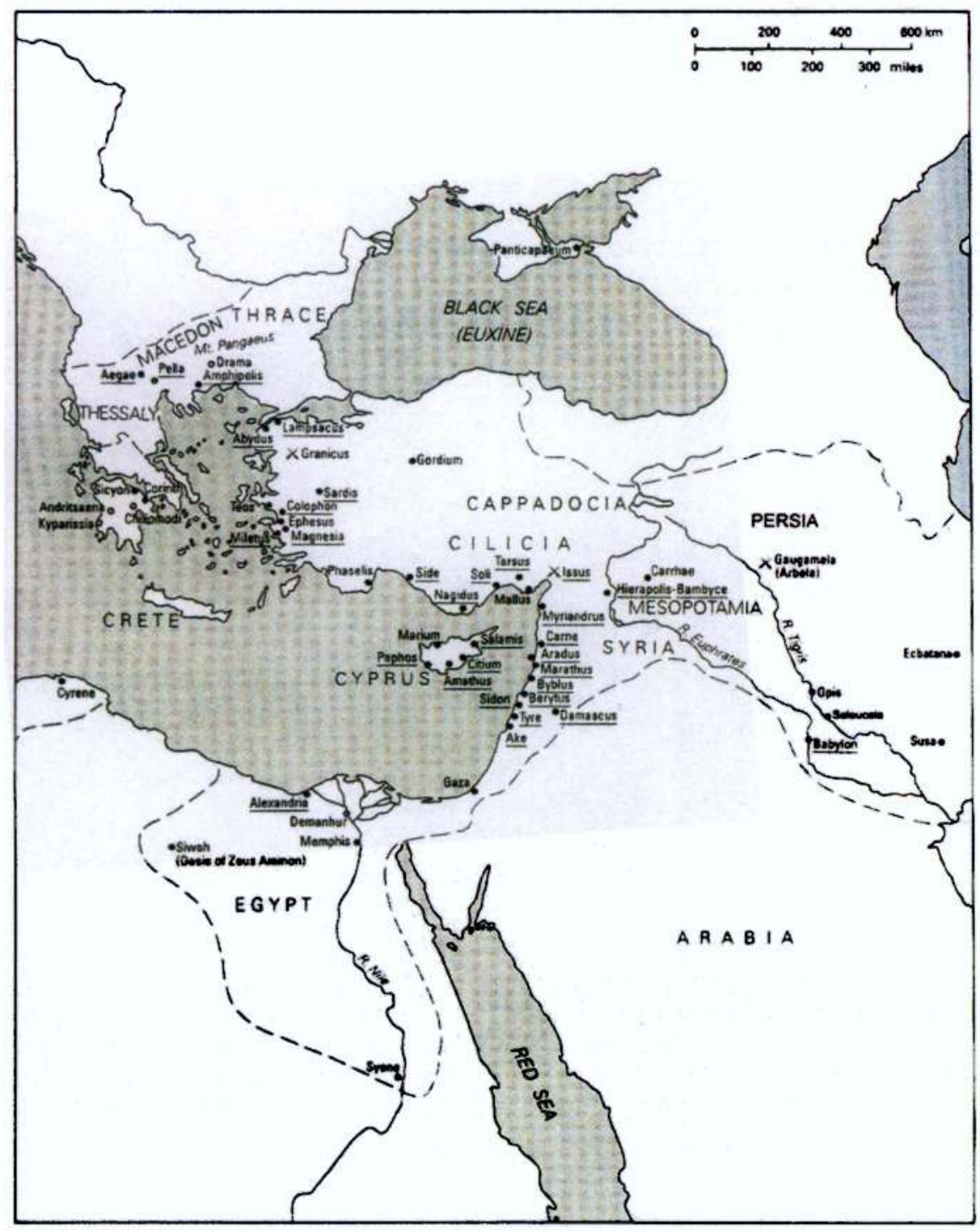

Harita 1: Büyük İskender' in Sikkelerinin Basıldığı Darphaneler 
Melih Arslan

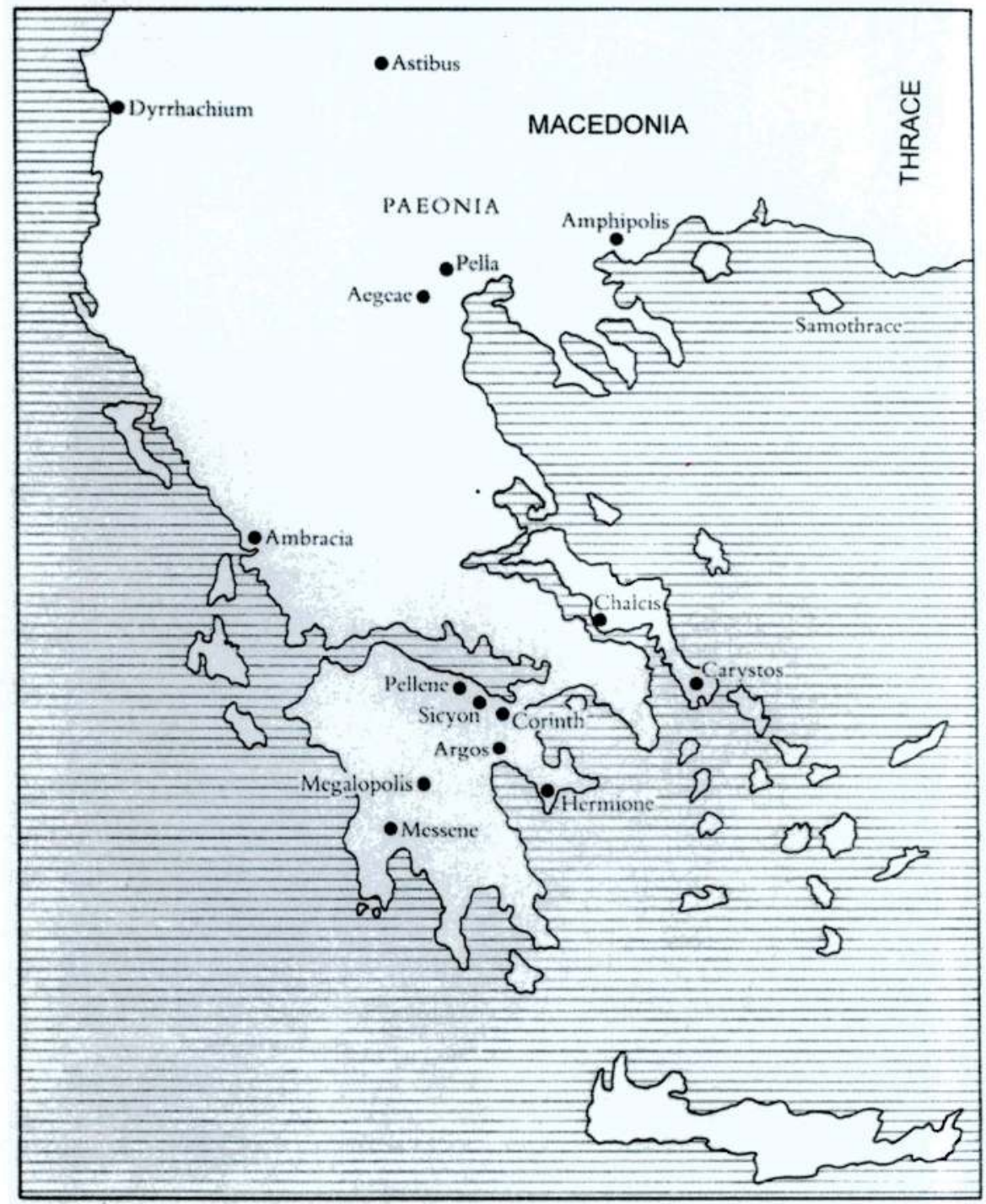

Harita 2: Makedonya ve Yunanistan Darphaneleri 
Melih Arslan

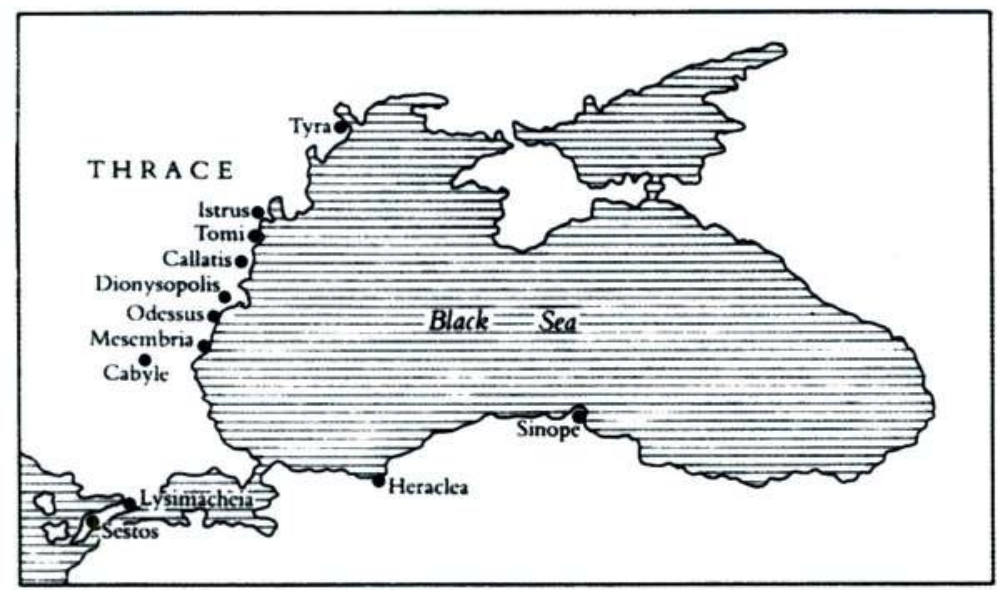

Harita 3: Karadeniz Kıyı Darphaneleri

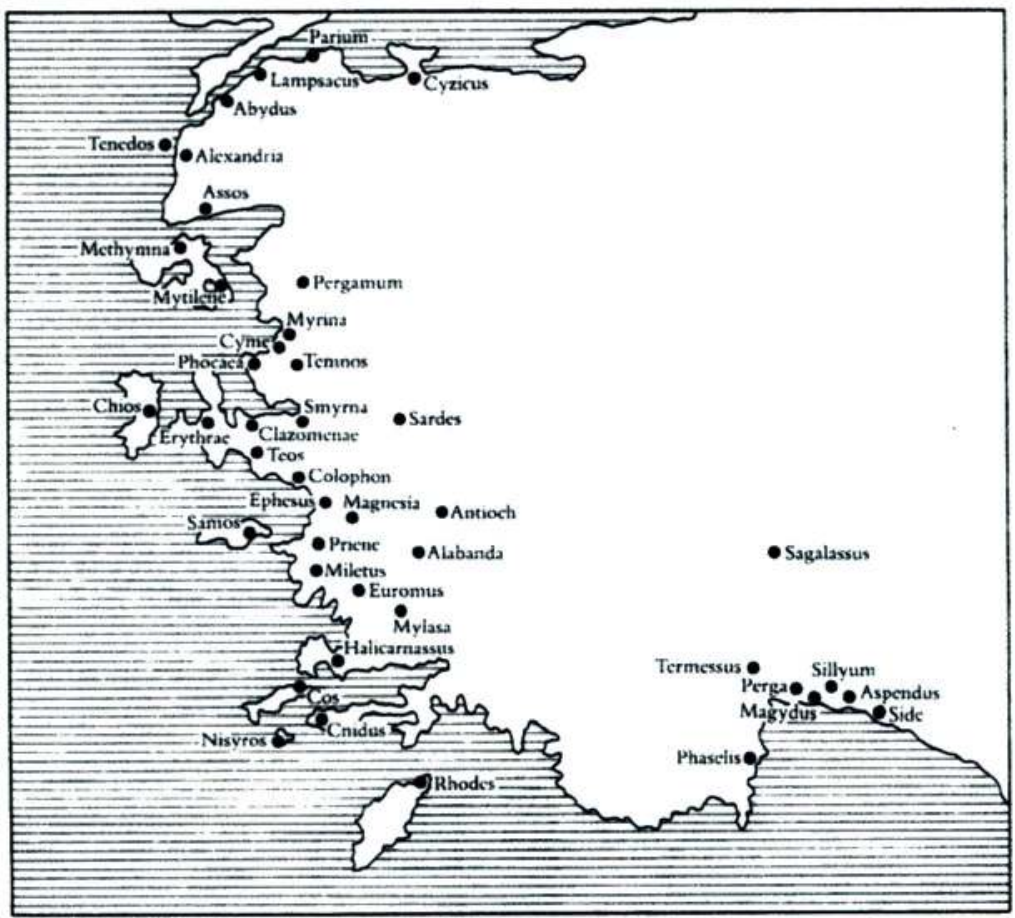

Harita 4: Batı ve Güney Anadolu Darphaneleri 


\section{Melih Arslan}

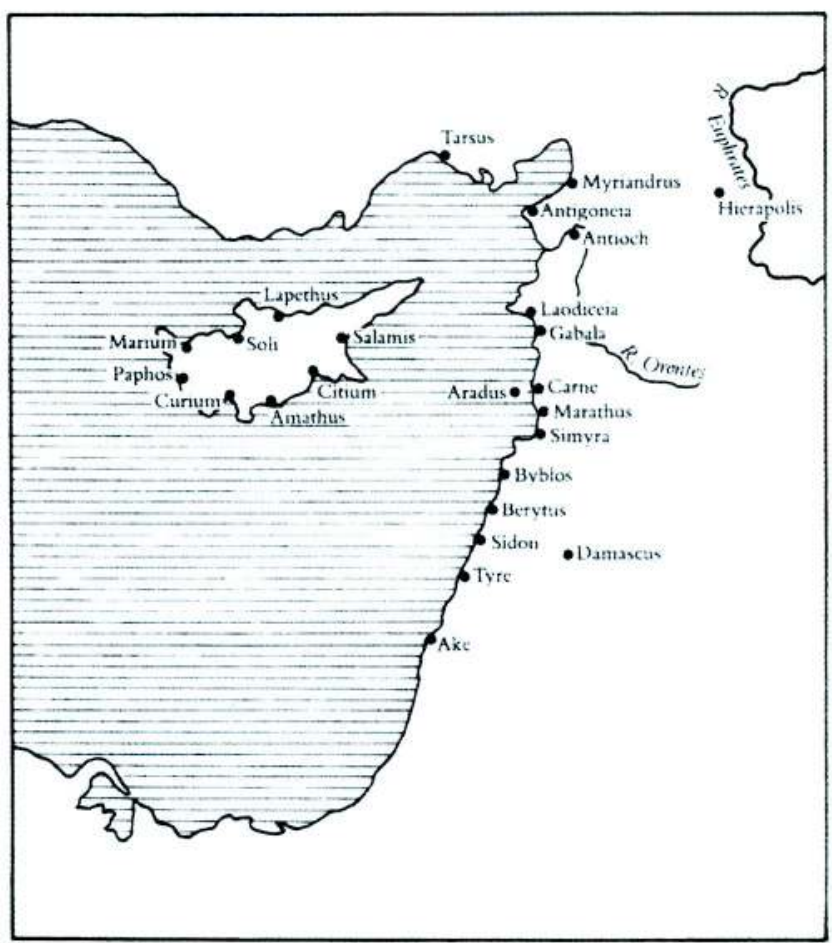

Harita 5: Kıbrıs ve Finike Bölgesi Darphaneleri

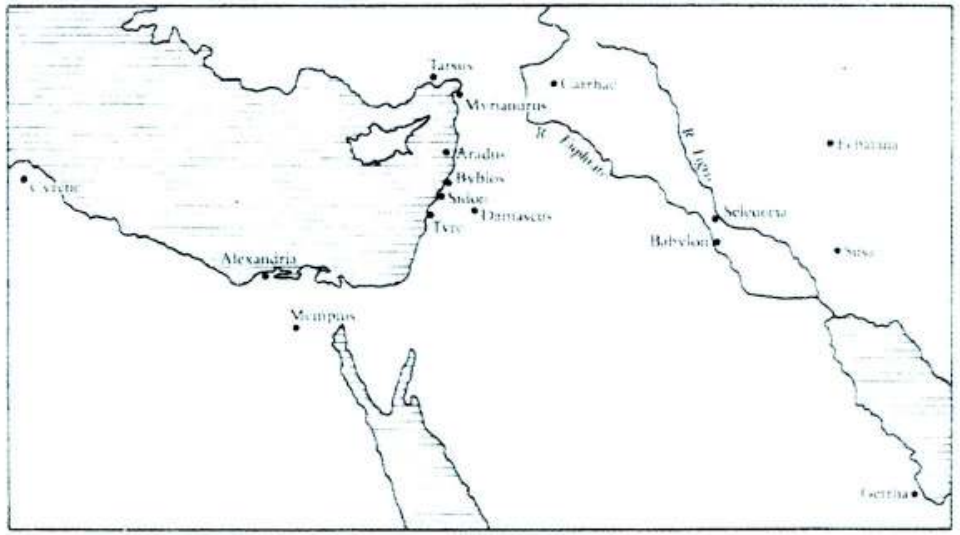

Harita 6: Afrika ve Doğu Darphaneleri 



Resim 1-2: Durmaz Definesi'nin Toplu Görünüşü 

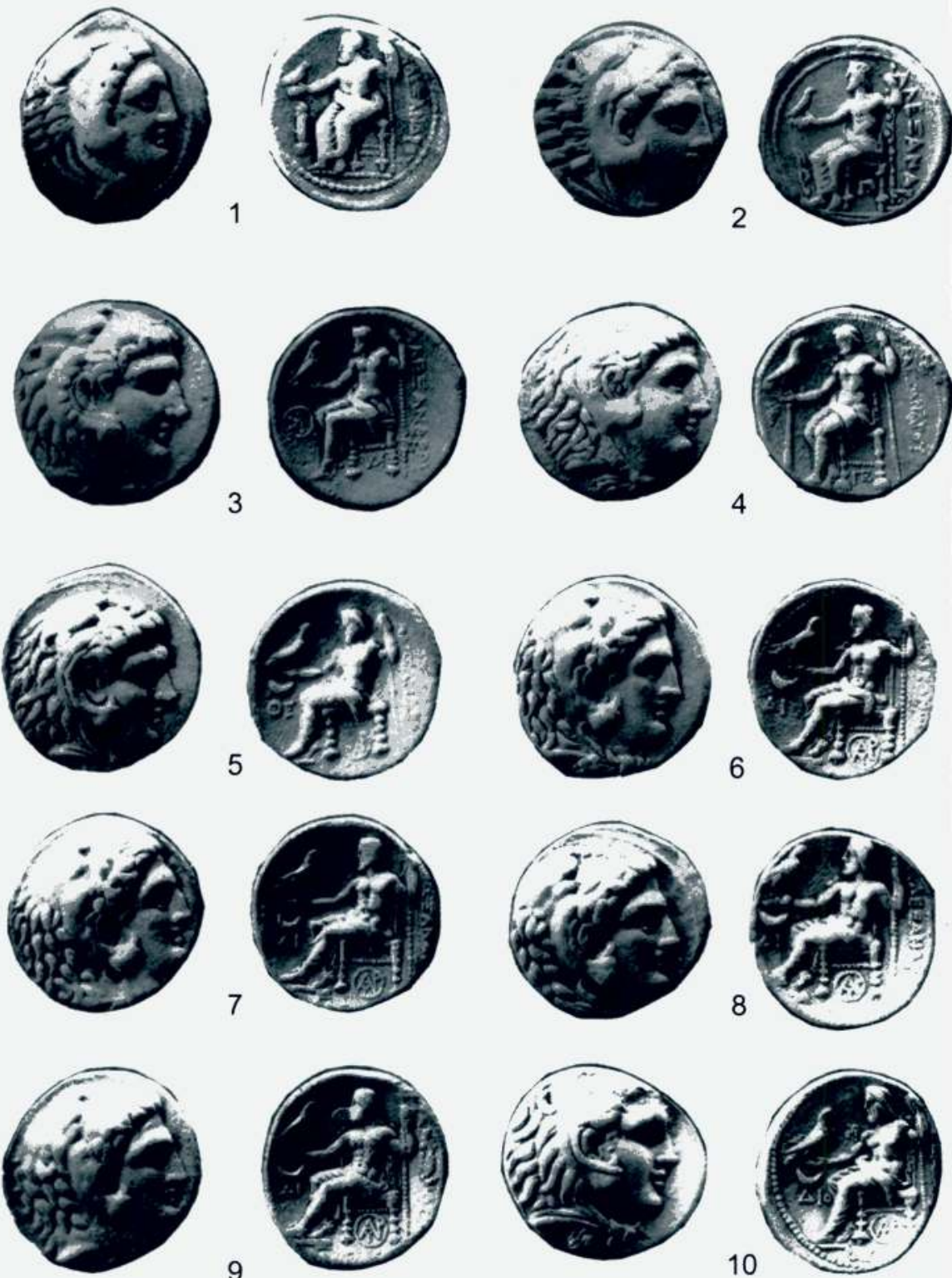

9
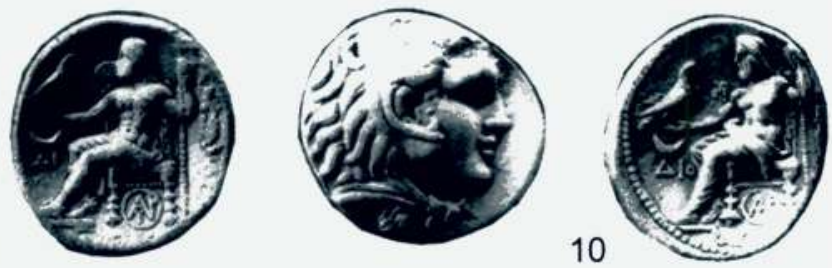

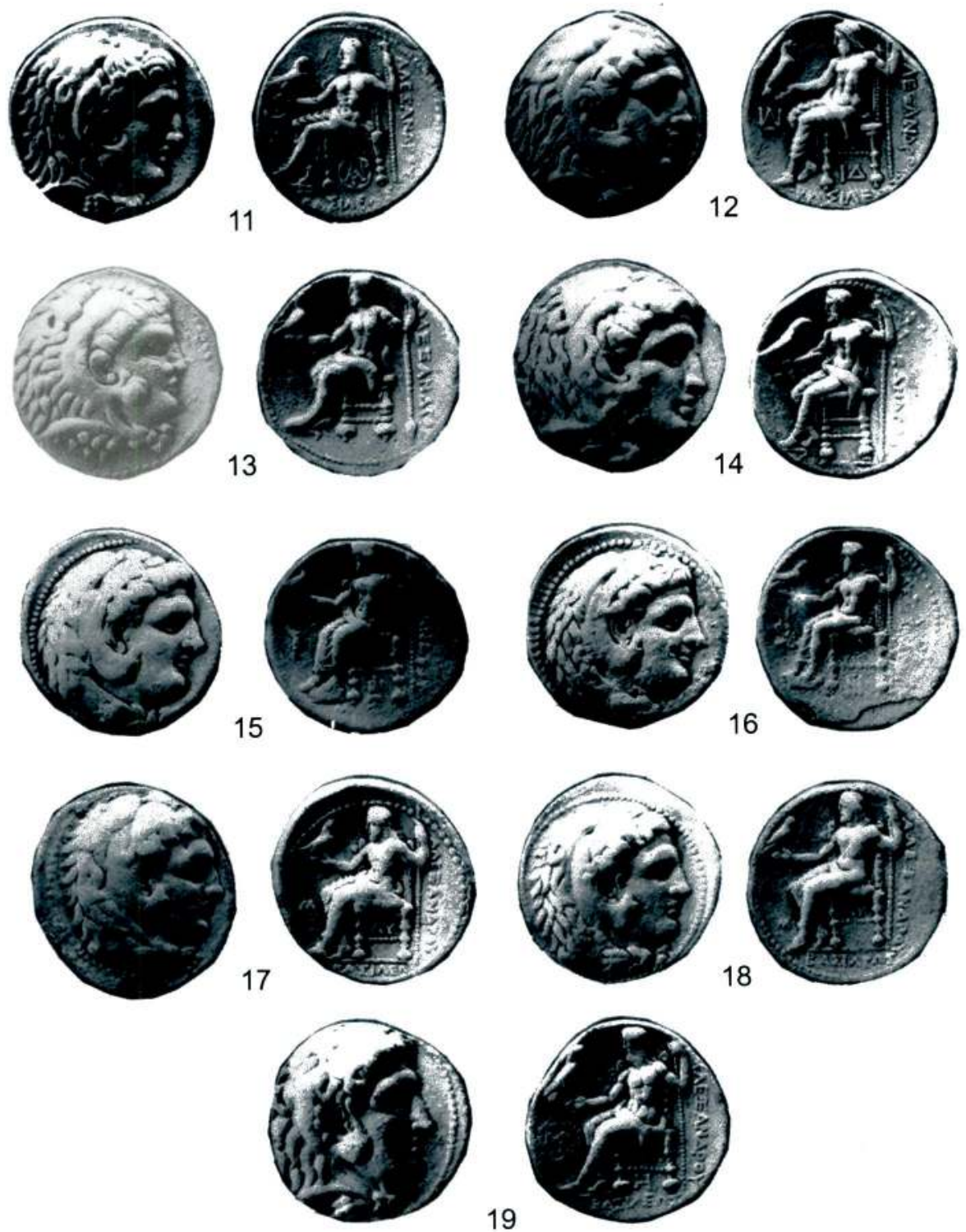

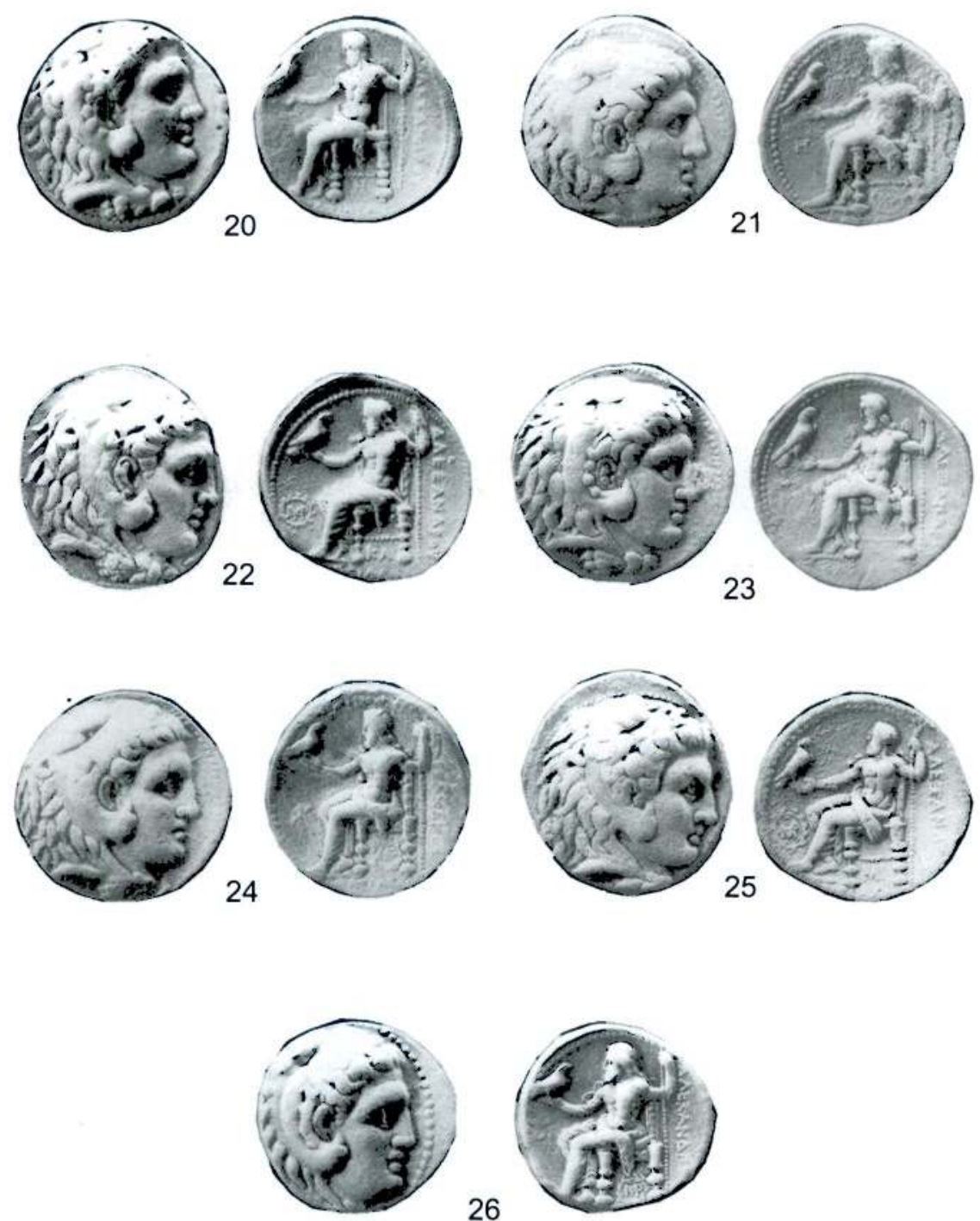


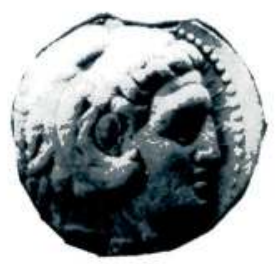

27
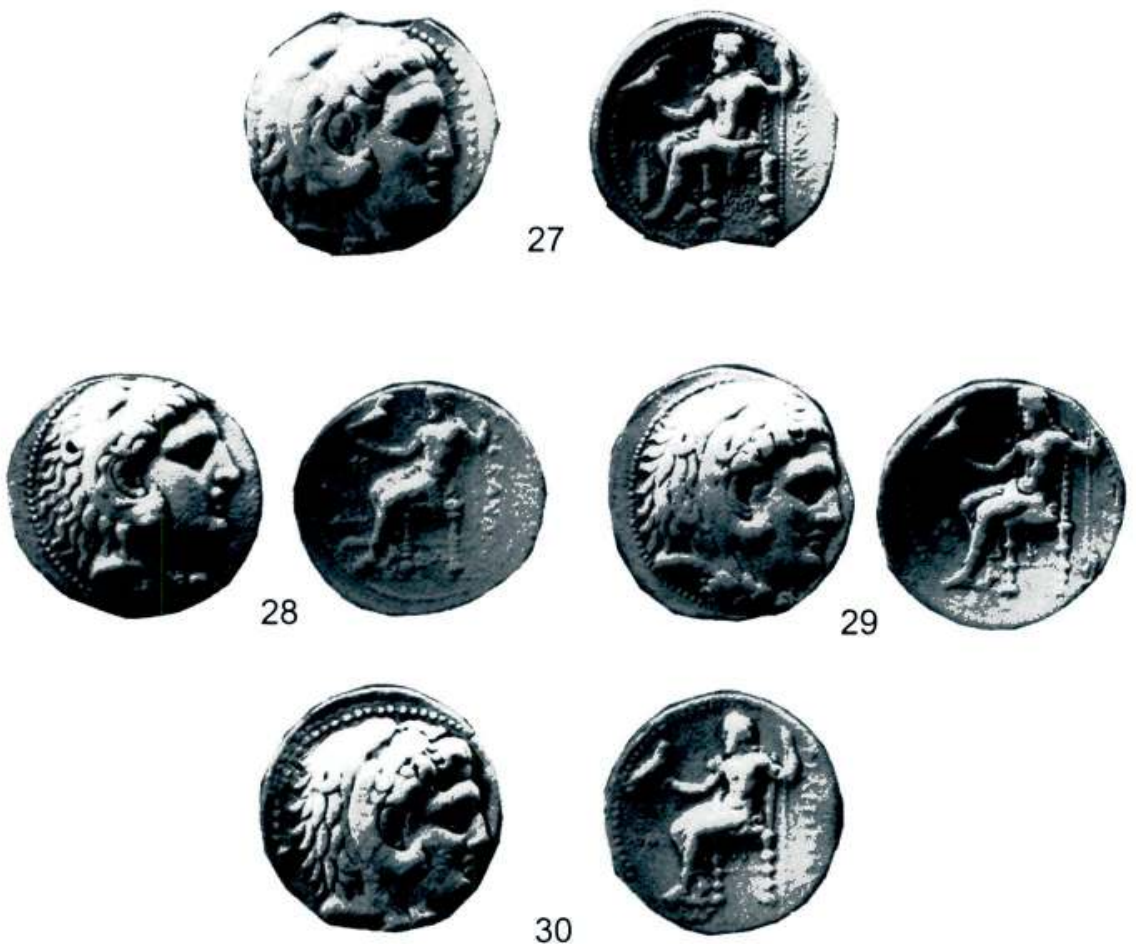

30
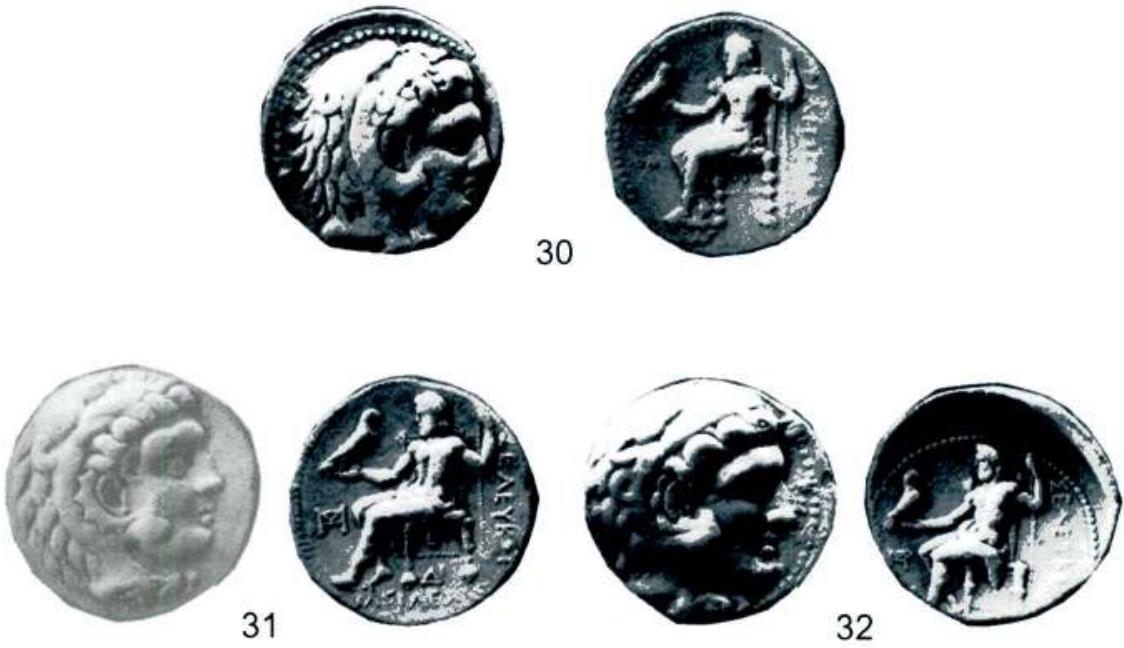
